\title{
Effects of Extracurricular Physical Activity on the Physical Fitness Levels of Youngsters in School Environments
}

\author{
Jéssica Barbosa ${ }^{1,2}$, Fernando Vieira ${ }^{1,2,3}$ and Marta Sousa ${ }^{1}$ \\ 1. ISEIT (Instituto Superior de Estudos Interculturais e Transdisciplinares de Almada), Piaget Institute 2805-059, Portugal \\ 2. LapCap -Learning and Cognition of Laboratory, Portugal \\ 3. RECI-Research in Education and Community Intervention, Portugal
}

\begin{abstract}
Extracurricular physical activity (EPA) complements the recommendations of daily physical activity and directly influences children's physical fitness. The main objective of this study was to understand the effect of EPA practice on students' physical fitness. It is a sample of 51 students of the fifth year schooling (62.7\% girls and $37.3 \%$ boys) with an average of 10.2 years of age. It is an observational study, with two groups, one of non-participation in EPA $=17$ and the other of participation in EPA = 34. Data collection was performed at a public school in the Lisbon area through the Fitnessgram Test Battery and a validated questionnaire for research purposes in order to understand the sociodemographic variables and practice of EPA. The cardiorespiratory variables, BMI and muscular strength were evaluated through specific tests of each physical capacity. The data were collected at the beginning and end of the school year. Between the two moments there were significant differences in all variables, assuming a non-significant value for the right inferior flexibility $p=0.149$. There was improvement in all variables except the BMI, which showed an increase at the end of the year, with a mean magnitude, $\mathrm{ES}=0.49$.
\end{abstract}

Key words: Physical fitness, physical activity, physical education, health and children.

\section{Introduction}

The daily practice of physical activity promotes many health benefits for children. In addition to developing and strengthening the musculoskeletal and cardiorespiratory systems, it develops social factors that facilitate the adoption of active and healthy habits and lifestyles. To achieve these results, this practice should be adequate to the recommendations that, according to the World Health Organization [1], are the accumulation of 60 minutes of moderate-intense physical activity daily, and for children of school age 30 minutes of this activity should be practiced in school [2]. However, the benefits are increased when the practice exceeds the recommended minimum

Corresponding author: Jessica Barbosa, master, professor, research fields: physical education, fitness physical, motor skills. values. Some studies show that the practice of physical activity in children and adolescents has shown a sharp decline, as well as the participation of adolescents in popular sports. In the school context, several studies also suggest that the operationalization and attention given to nonphysical physical education do not adequately correspond to its real importance [3].

Physical activity for children and adolescents includes classes in physical education, sports, transportation, domestic tasks, leisure activities and planned exercises [2].

Physical education classes are a great potential to ensure the practice of adequate physical activity, promoting active and healthy habits in the lives of children and adolescents [4]. In this perspective, Fitnessgram [5] is an instrument of physical activity and physical fitness that is used in curricular context, aiming to understand the level of physical fitness of the 
students, visioning to identify possible health risks according to the indicators of fitness aerobic, body composition, muscular strength, muscle resistance, and flexibility. These levels are determined by reference intervals that provide the information corresponding to the physical fitness zone in which the student is in the different tests, i.e., below the healthy zone of physical fitness, healthy zone of physical fitness and above the healthy zone of physical fitness [6].

Most cardiorespiratory and metabolic problems are directly related to the low level of physical activity at the curricular and/or extracurricular level. Quality physical education contributes to the daily accumulation of physical activity and is particularly important for children who are overweight or who do not have access to these opportunities in the home environment [7].

Currently, physical education classes are the appropriate moments for all children to engage in moderate-vigorous intensity physical activity with safety due to the structured educational environment supervised by specialized professionals.

The conceptual framework of the curricular model is designed around the health-related components of cardiorespiratory fitness, muscular strength and endurance and flexibility [7]. According to some studies, it is suggested that physical education curricular that includes physical fitness activities can significantly increase the amount of time spent in vigorous or moderate intensity physical activity, responding to some pathological problems, and bringing benefits to children's health [8]. In this perspective, the Center for Disease Control and Prevention supports this view, since physical education provides students with the tools to establish and maintain a physically active and healthy lifestyle throughout life [9].

Although the curricular context is important for the promotion and practice of physical activity, only 50\% of the recommended practice is directed to the school context, and the other part must be carried out in an extracurricular context, in order to ensure the minimum practice recommendations [8].

The main objective of this study was to understand the effects of the practice of extracurricular physical activity on the physical fitness of the students, through the cardiorespiratory indicators, body composition, muscular fitness and flexibility, evidencing the benefits that this practice promotes when accumulated with the classes of physical education.

We state as hypotheses:

(I) Overall, students improve in all areas of physical fitness throughout the school year.

(II) Students who practice EPA have better physical fitness scores than those who do not practice EPA.

\section{Methods}

\subsection{Types of Study}

It is an observational study carried out during the school year and characterized by two study groups submitted to two-stage test application. A group corresponded to the students who practiced physical activity only in a school context and the other group was constituted by the students who, besides physical education classes, practiced extracurricular physical activity in the form of distinctive characteristics (leisure, sports, means of transport, etc.).

This study results from a final investigation of the degree in Physical Education and Sport, carried out in a public school in the Lisbon area.

\subsection{Sample}

The eligibility criterion was to belong to the 5 th grade and within this group, there were no exclusion criteria. The sample consisted of 51 students from the 5 th grade in a public school in the Lisbon area, in which girls represent $62.7 \%$, the average age being 10.2 years. It is an observational study, with two groups, one of non-participation in EPA $=17$ and the other of non-participation in EPA $=34$.

Both the educational institution and the parents authorized the collection of data and signed the 
authorization.

\subsection{Instruments}

As it was a study during the school year, data were collected at the beginning (moment 1 ) and at the end (moment 2) of the year. Initially, it applied the Fitnessgram Test Battery and a questionnaire of the practice, time and weekly frequency of extracurricular physical activity practice. After moment 1 , the physical education classes went as usual, as well as the students' daily lives; at the end of the school year, moment 2 , students were again subjected to battery testing. Regarding the questionnaires, these were applied after the cardiorespiratory fitness test. The cardiorespiratory fitness test was isolate performed in the 45-minute classes, since the application of the other physical tests could interfere and condition the students' performance. The remaining tests were applied in the 90-minute classes together with the areas of body composition, muscular endurance and flexibility.

For the evaluation of the body composition, there were collected anthropometric measures and used under the body mass index formula (weight/height ${ }^{2}$ ). The cardiorespiratory fitness was evaluated through the Vaivem test, expressed in terms of oxygen consumption, $\mathrm{VO}_{2}(\mathrm{~mL} / \mathrm{kg} / \mathrm{min})=0.353 \times$ courses $1.112 \times$ age +45.619 ; muscular endurance through abdominal tests, extension of arms and trunk extension and flexibility through the tests sits and reach and flexibility of the shoulders.

\subsection{Statistical Procedures}

The following statistical techniques were used: (i) analysis of normality using the Kolmogorov-Smirnov test, because the sample is higher than 50; (ii) measures of central tendency and dispersion; (iii) Wilcoxon Signed Rank Test for paired samples for comparison between two moments of a group; (iv) Mann Whiney $U$ Test for independent samples for comparison of two groups, using percentages of difference between the two moments of each dependent variable; (v)
Chi-square test for comparison of BMI categories. The Effect Sizes (ES), i.e., the different magnitudes of the effects, were calculated by means of the Cohen coefficient, in addition to the comparison tests. For all tests, it was defined type I error for $p=0.05$.

\section{Results}

In the first place, we analyzed the normality of the variables under study, and it was verified by the Kolmogorov-Smirnov test that the distributions were non-normal, $p<0.05$. Thus, the statistical tests used were all non-parametric.

Table 1 shows the values of the different variables at the beginning and end of the school year. Comparing these two moments, it is verified that there are significant differences in all physical fitness variables, except for the lower right flexibility, $p=0.149$. In all the variables under study there is improvement, except in the BMI where there was an increase at the end of the year, with an average magnitude, $\mathrm{ES}=0.49$. The magnitude of the effect is very strong concerning the trunk extension, average for cardiorespiratory fitness, abdominal strength and arm extension, being weak for lower left flexibility, $\mathrm{ES}=0.23$.

We then separately studied the two groups that make up the sample. Table 2 shows the results for the group of students practicing extracurricular physical activity.

Comparing the two moments for the EPA group, there are significant differences in all physical fitness variables, except for the lower right flexibility, $p=$ 0.695. It is verified that the magnitude of the effect is very strong for the trunk extension ES $=1.21$, and weak for the lower left flexibility, $\mathrm{ES}=0.22$. There was improvement in all variables, except in the BMI, where there was an increase at the end of the year, with an average magnitude, $\mathrm{ES}=0.58$.

Table 3 shows the results for the group of students who did not practice EPA and there were significant differences between the two moments, with improvements in all variables at the end of the year, except for the lower left flexibility $p=0.440$. The 
magnitude of the effect for abdominal force is the highest $\mathrm{ES}=0.75$, with $\mathrm{ES}=0.65$ for arm extension and low for left inferior flexibility $\mathrm{ES}=0.23$.

Complementarily, in Table 4, we compared the two groups at the end of the year, according to the percentage of difference from the beginning to the end of the school year, in each of the variables under study. We found significant differences in the trunk extension variable $p=0.009$, with a very strong magnitude of $\mathrm{ES}=-0.88$, and a mean of 21.1 for the EPA group.

Table 1 Comparison between the beginning and end of the school year.

\begin{tabular}{llccc}
\hline & \multicolumn{1}{l}{ Beginning of the school year } & End of the school year & \multicolumn{2}{l}{} \\
\cline { 2 - 4 } & \multicolumn{1}{c}{$n=51$} & $n=51$ & $p$ & ES \\
\cline { 2 - 4 } & Average \pm SD & Average \pm SD & $<0.001$ & 0.49 \\
Body mass index $\left(\mathrm{kg} / \mathrm{m}^{2}\right)$ & $18 \pm 3.6$ & $19.7 \pm 3.4$ & $<0.001$ & 0.30 \\
Cardiorespiratory fitness $(\mathrm{mL} / \mathrm{kg} / \mathrm{min})$ & $44.8 \pm 4.6$ & $46.3 \pm 5.4$ & $<0.001$ & 0.46 \\
Abdominal strength & $20.9 \pm 13.5$ & $28.0 \pm 16.9$ & $<0.001$ & 0.42 \\
Arms extension & $10.9 \pm 7.4$ & $14.3 \pm 8.6$ & $<0.001$ & 0.88 \\
Trunk extension & $22.6 \pm 3.6$ & $26.1 \pm 4.3$ & 0.149 & 0.15 \\
Lower right flexibility & $24.6 \pm 6.0$ & $25.5 \pm 6.3$ & 0.041 & 0.23 \\
Lower left flexibility & $23.7 \pm 6.8$ & $25.2 \pm 6.5$ &
\end{tabular}

SD—standard deviation; ES—effect size; $p-p$ value for Wilcoxon Signed Rank Test for paired samples.

Table 2 Comparison between the beginning and end of the school year for the group that practices EPA.

\begin{tabular}{|c|c|c|c|c|}
\hline & Beginning of the school year & End of the school year & & \\
\hline & $n=34$ & $n=34$ & & \\
\hline & Average $\pm \mathrm{SD}$ & Average \pm SD & $p$ & ES \\
\hline Body mass index $\left(\mathrm{kg} / \mathrm{m}^{2}\right)$ & $17.4 \pm 3.0$ & $19.3 \pm 3.5$ & $<0.001$ & 0.58 \\
\hline Cardiorespiratory fitness $(\mathrm{mL} / \mathrm{kg} / \mathrm{min})$ & $46.0 \pm 4.6$ & $47.7 \pm 5.4$ & $<0.001$ & 0.34 \\
\hline Abdominal strength & $24.5 \pm 13.0$ & $30.2 \pm 18.0$ & 0.007 & 0.36 \\
\hline Arms extension & $12.2 \pm 8.1$ & $15.5 \pm 9.5$ & 0.009 & 0.37 \\
\hline Trunk extension & $22.4 \pm 3.2$ & $26.8 \pm 4.0$ & $<0.001$ & 1.21 \\
\hline Lower right flexibility & $25.2 \pm 6.0$ & $25.6 \pm 6.8$ & 0.695 & 0.06 \\
\hline Lower left flexibility & $23.9 \pm 7.2$ & $25.5 \pm 4.2$ & 0.059 & 0.22 \\
\hline
\end{tabular}

SD—standard deviation; ES—effect size; $p-p$ value for Wilcoxon Signed Rank Test for paired samples.

Table 3 Comparison between the beginning and end of the school year for non-practices EPA group.

\begin{tabular}{|c|c|c|c|c|}
\hline & Beginning of the school year & End of the school year & & \\
\hline & $n=17$ & $n=17$ & & \\
\hline & Average \pm SD & Average \pm SD & $p$ & ES \\
\hline Body mass index $\left(\mathrm{kg} / \mathrm{m}^{2}\right)$ & $19.1 \pm 4.5$ & $20.4 \pm 3.1$ & 0.022 & 0.34 \\
\hline Cardiorespiratory fitness $(\mathrm{mL} / \mathrm{kg} / \mathrm{min})$ & $42.3 \pm 3.6$ & $43.6 \pm 4.3$ & 0.068 & 0.33 \\
\hline Abdominal strength & $14.2 \pm 11.4$ & $23.7 \pm 13.8$ & 0.013 & 0.75 \\
\hline Arms extension & $8.3 \pm 4.9$ & $11.9 \pm 6.1$ & 0.005 & 0.65 \\
\hline Trunk extension & $23.2 \pm 4.4$ & $24.7 \pm 4.6$ & 0.053 & 0.33 \\
\hline Lower right flexibility & $23.4 \pm 5.8$ & $25.2 \pm 5.4$ & 0.062 & 0.32 \\
\hline Lower left flexibility & $23.2 \pm 6.2$ & $24.5 \pm 5.2$ & 0.440 & 0.23 \\
\hline
\end{tabular}

SD—standard deviation; ES—effect size; $p-p$ value for Wilcoxon Signed Rank Test for paired samples. 
Table 4 Comparison between the beginning and end of the school year for both groups.

\begin{tabular}{|c|c|c|c|c|}
\hline & Beginning of the school year & End of the school year & & \\
\hline & $n=34$ & $n=17$ & & \\
\hline & Average \pm SD & Average \pm SD & $p$ & ES \\
\hline Body mass index $\left(\mathrm{kg} / \mathrm{m}^{2}\right)$ & $11.1 \pm 8.7$ & $9.3 \pm 11.5$ & 0.704 & -0.18 \\
\hline Cardiorespiratory fitness $(\mathrm{mL} / \mathrm{kg} / \mathrm{min})$ & $3.6 \pm 5.8$ & $3.1 \pm 7.4$ & 0.689 & -0.08 \\
\hline Abdominal strength & $35.6 \pm 66.3$ & $224.0 \pm 415.7$ & 0.262 & 0.63 \\
\hline Arms extension & $79.0 \pm 169.7$ & $86.5 \pm 135.3$ & 0.395 & 0.05 \\
\hline Trunk extension & $21.1 \pm 13.2$ & $8.0 \pm 16.5$ & 0.009 & -0.88 \\
\hline Lower right flexibility & $1.9 \pm 13.2$ & $11.9 \pm 29.5$ & 0.18 & 0.44 \\
\hline Lower left flexibility & $9.9 \pm 25.5$ & $12.0 \pm 43.6$ & 0.638 & 0.06 \\
\hline
\end{tabular}

SD—standard deviation; ES—effect size; $p-p$ value of $\mathrm{p}$ for Mann Whiney $U$ Test for independent samples.

\section{Discussion}

The main objective of the study was to understand the effects of the practice of extracurricular physical activity in the domains of physical fitness of the youngsters in school context. In order to be possible of the comparison of the study, these youngsters have been evaluated at the beginning and the end of the school year.

All the students in the sample practiced physical activity, one group had this practice only in physical education classes, and the other, cumulatively, practiced extracurricular physical activity. Overall, statistically there were observed significant differences in both groups and in all domains studied, except for the lower right flexibility. There was improvement in all domains studied, however, there was an increase in BMI at the end of the year. The practice of physical activity is fundamental to the promotion of active and healthy lifestyles and, although the recommendations of the World Health Organization are 60 minutes daily, any practice that contravenes the sedentary habits, promotes benefits and physical [2]. We then compared the two moments of each group separately. In the group that practiced EPA, there were observed significant differences in all variables, except for flexibility and lower right flexibility. The increase in BMI continued to be observed at the end of the year, however, all the other variables showed improvements, with the effect of extracurricular physical activity being stronger in the muscular domain. We have checked that the benefits of physical activity practice are increased when the practice exceeds recommended minimum values, being important an extracurricular investment [7].

According to the results, the group that did not practice EPA also presented improvements in the domains studied. The effects were stronger in the muscular domain, and medium in the cardiorespiratory domain. These results demonstrate that physical education classes are an enormous potential to ensure the practice of adequate physical activity, promoting active and healthy habits in the lives of children and adolescents [4]. Quality physical education contributes to the daily accumulation of physical activity and is particularly important for children who do not have access to these opportunities in the home environment [7].

The practice of physical activity, however minimal, promotes health benefits for students, which increase the importance of physical education classes in their active and healthy life [2]. In general, we verified that all students improved in all areas of physical fitness throughout the school year, confirming the first hypothesis of the study.

Separately, both groups presented significant differences in the studied variables, presenting improvements in the physical fitness domains at the end of the school year. We checked that the comparison between the two groups at the end of the year, 
according to the percentage of difference from the beginning to the end of the school year, showed a significant difference in the trunk extension variable, with a magnitude of the very high effect, having better values the group that practiced EPA, which proves the second hypothesis.

The results of the study show the effects that the practice of physical activity promotes on the physical fitness of the students.

The battery of tests we used in the study is a tool used in the school context, which allows teachers to understand the level of physical fitness that students are in, i.e., above the healthy zone of physical fitness, healthy zone of physical fitness or below the healthy zone of physical fitness, to try to solve their needs, promoting improvement in all areas covered [6]. In this way, it is permissible to affirm that physical education classes are an enormous potential to ensure the practice of adequate physical activity, promoting active and healthy habits in the life of children and adolescents [4]. However, its importance has not been given due attention, and the failures in the operationalization of the subject have been problematic in the school context [3]. This leads us to conclude that, in addition to a curricular investment, it is very important to have an extracurricular investment, so that the practice of physical activity is regular, promoting active and healthy lifestyles in children and adolescents [2].

Some limitations of the study should be noted. The first relates to the reduced population of the study, and

\section{References}

[1] World Health Organization. 2010. Global Recommendations on Physical Activity for Health. Geneva: WHO Library Cataloguing.

[2] American College of Sports Medicine. 2015. Physical Activity in Children and Adolescents. ACSM.

[3] Institute of Medicine. 2013. Educating the Student Body: Taking Physical Activity and Physical Education to School. the other relates to the technique of measuring body composition., We only used the BMI ( $\mathrm{kg} /$ height $\left.^{2}\right)$, not considering the percentage of fat mass and muscle mass alone. The second limitation is of fundamental importance, since BMI values are limited, not making a distinction between the amount of fat and muscle mass. Considering body mass in its entirety, this may explain the increase in BMI between the beginning and end of the year in the presented results.

The study and the results found can be applied and compared with other populations, with different dimensions and characteristics, with the objective of broadening scientific knowledge in this area.

\section{Conclusions}

As a conclusion, students who practice extracurricular physical activity have a higher physical fitness than students who do not practice. However, students who only practice physical activity in a school context, also present improvements in the domains studied. We also conclude that all the time spent in extracurricular physical activity can be accumulated with daily practice, thus promoting a better physical fitness and, consequently, an improvement in health and well-being.

\section{Acknowledgements}

This work is financed by national funds of FCT-Fundação para a Ciência e a Tecnologia, I.P., in the scope of the project UID/ Multi/04587/2019.
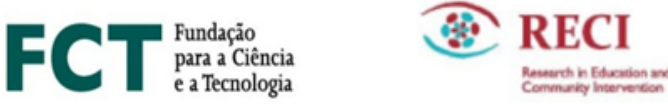

Washington, DC: The National Academies Press.

[4] Centers for Disease Control and Prevention. 2001. "Increasing Physical Activity: A Report on Recommendations of the Task Force on Community Preventive Services." Morbidity and Mortality Weekly Report 50: 1-13.

[5] Faculdade de Motricidade Humana. Núcleo de Exercício e Saúde. Programa Fitnessgram. Retrieved from http://www.labes.fmh.utl.pt/programas/fitnessgram/index 
2.htm.

[6] Plowman, S. A., and Meredith, M. D. 2013.

Fitnessgram/Activitygram Reference Guide, 4th ed. Dallas, TX: The Cooper Institute.

[7] Society of Health and Physical Educators. 2013. National Standards for K-12 Physical Education. Reston: SHAPE America.

[8] Society of Health and Physical Educators. 2012.
Instructional Framework for Fitness Education in Physical Education [Guidance Document]. Reston: SHAPE America.

[9] Wang, G., Pereira, B., and Mota, J. 2006. A Atividade Física das crianças e a Condição física relacionada com a saúde: Um estudo de caso em Portugal. In B. Pereira \& G. S. Carvalho (Coord.). Educação Física, Saúde e Lazer: A infância e estilos de vida saudáveis. Lisboa: LIDEL, Edições técnicas, Lda, pp. 141-9. 